\title{
A Retrospective Evaluation of College ELT Textbooks in China
}

\author{
Xiaofei Tang \\ School of Foreign Languages \\ Wuhan University of Technology \\ Wuhan, China \\ xiao-fei.tang@whut.edu.cn
}

\author{
Diyang Zheng \\ School of Foreign Languages \\ Wuhan University of Technology \\ Wuhan, China
}

\begin{abstract}
The role of teaching materials is crucial to English learning in foreign language settings such as Mainland China. Since the number of textbooks published on the market is huge and the qualities are heterogeneous, it is necessary to know how to select a textbook suitable for students to meet the pedagogical requirements. Motivated by McDonough \& Shaw's (2003) twoprocedure evaluation model, this study aims to conduct a retrospective evaluation of two English textbooks that have been widely used among the universities in China-Contemporary College English and $A$ New English Course. The evaluation seeks to measure the actual effects of these textbooks on users through questionnaires and interviews. The results reveal that these textbooks remain problems such as the length of passages and the number of translation exercises.
\end{abstract}

Keywords-Retrospective evaluation; Textbook evaluation; College English; L2 teaching; ELT

\section{INTRODUCTION}

Based on the Guidelines of the National Program for Medium- and Long-Term Educational Reform and Development (2010-2020) [1] and Some Opinions on Improving the Quality of Higher Education in All-Round Way (2012) [2], the Guide to College English Teaching (2017) [3] was proposed to offer a series of pedagogical advices for English education at a university level in China. With respect to the curriculum resources, the Guide to College English Teaching (2017) [3] points out that language textbooks are the main carrier of teaching content as well as the basic guarantee for achieving teaching objectives.

The abundance of language textbooks available on the current educational market does not make it easy for teachers to select appropriate textbooks for English courses they teach in universities. Textbook selection may have crucial effects on English teaching and learning process, since teachers may utilize textbooks as guidelines for their classroom teaching [4] [5] or plan and organize the whole language syllabus around them [6] [7]. The choice of textbooks may be associated with the achievement of teaching objectives. To choose the textbooks that best contribute to English teaching, it is paramount to carry out an assessment based on valid and reliable principles or approaches [8-9].

The present study aims to conduct a retrospective assessment of two English textbooks Contemporary College
English and $A$ New English Course which have been widely used across the universities for English majors in Mainland China. Following [10] two-procedure assessment model, the current evaluation seeks to measure the actual effects of these textbooks on the users through a questionnaire and an interview. This can help us to improve the effectiveness of English teaching for tertiary education, work out a more adaptive teaching program and accumulate the experience to choose the suitable textbooks.

\section{MCDONOUGH \& SHaW’S (2003) Evaluation Model}

Reference [10] generated a two-procedure evaluation model of English language teaching (ELT) teaching materials through the checklist method. Compared to the previous studies on textbook evaluation [11-12], [10] further extended the scope of textbook assessment by incorporating an external evaluation into their model. Their model consists of two procedures. The first procedure is an external overview of how the textbooks have been organized as claimed by the writers or publishers through the cover, table of contents statements, and introduction. The main criteria to be considered in the external evaluation include: the intended audience (e.g., young learners or mature adults), the proficiency level (e.g., for beginners or advanced learners), the context in which the language materials are to be used (e.g., teaching English for Academic Purposes or Business Purposes), the presentation of language and organization of lessons, the textbook writer's perceptions of language and methodology, and the layout. The second procedure is an internal evaluation aimed at seeing how far the textbooks live up to the claims stated by the writers with respect to different features. For the internal assessment, some relevant criteria to examine the consistency between the writers' claims and the internal content are: the presentation of language skills in the materials, authenticity of dialogues or exercises, suitability for different learning styles.

Based on the two types of assessment above, the evaluators can conduct an overall assessment that generalizes the suitability of the materials for teachers and learners. Reference [10] evaluation paradigm contributes to assisting teachers to identify strengths and shortcomings in the materials within a given working context. Their paradigm distinguishes the purposes behind the procedural evaluation and appears to be more realistic for teachers to put it into practice. Reference [10] also emphasizes the proactive engagement of teachers in the 
process of textbook evaluation through the systematic use of checklist of pertinent criteria.

The plausibility of [10] evaluation model has been tested and generally supported by a large number of empirical studies on textbook assessment [13-17].

\section{Methodology}

\section{A. The Selected Textbooks}

The Contemporary College English [18] was published by Foreign Language Teaching and Research Press. There are 15 units in all. This textbook is designed for the compulsory course for undergraduate students from grade one to grade four of the English majors. It aims to cultivate students' basic English skills to understand the similarities and differences between Chinese and Western languages and cultures, and to develop their language and communicative competence on the basis of strong English language.

A New English Course [19] was published by Shanghai Foreign Language Education Press. There are 20 units in all. It is compiled in the new situation of the reform and development of higher education, drawing on the experience of the previous English primary course, and aiming at the new goals and requirements of the self-study examination of higher education. This coursebook selects authentic materials. Each unit consists of dialogues, texts, word lists, annotations, grammar, pronunciation, practices and so on. It seeks to provide a full range of learning support for the students including the enhancement of English linguistic knowledge and the cultivation of cross-cultural awareness.

\section{B. Instrument: Questionnaires}

The present textbook assessment is achieved via a questionnaire which is adapted on the basis of [10] twoprocedure evaluation model. The questionnaire contains 16 questions altogether. As indicated in Table 1, Questions 1-4 focus on the information of the respondents such as their majors, gender, grade, etc. Questions 5-16 are the key part of the questionnaire and focus on the textbook content such as sources of the passages and exercises. Questions 5-14 are single-choice items, while Questions 15-16 allow the informants to offer their own answers.

TABLE I THE QUESTIONNAIRE USED FOR THE TEXTBOOK ASSESSMENT

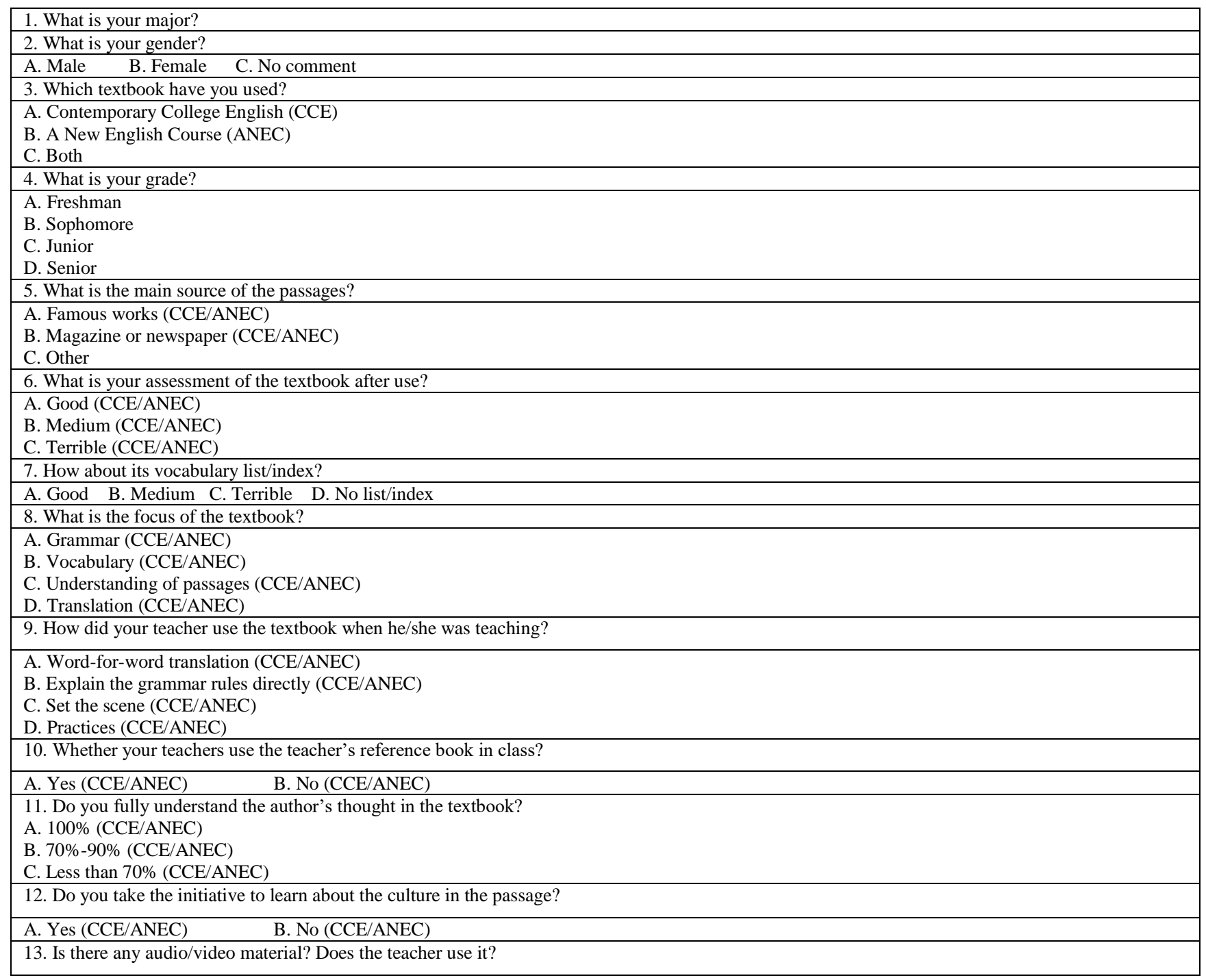




\begin{tabular}{|l|}
\hline \\
\hline A. Yes; yes (CCE/ANEC) \\
B. Yes; no (CCE/ANEC) \\
C. No; yes (CCE/ANEC) \\
D. No; no (CCE/ANEC) \\
\hline 14. Did you find that the exercises and tests are difficult or easy? \\
\hline A. Difficult (CCE/ANEC) B. Easy (CCE/ANEC) \\
\hline 15. Compared with the teacher's use of material in class, how about your self-study with this textbook? \\
\hline 16. Your opinions on this textbook. \\
\hline
\end{tabular}

\section{Informants}

The questionnaire aimed to receive the feedback from the senior students of English majors in Wuhan University of Technology. The reason why the senior students were chosen as the informants is that they had used either of the two textbooks over the past four years and had a detailed understanding of the actual effects of the textbooks. Among the informants, there were 17 male students and 56 female students.

\section{Procedures}

The researchers printed out 110 hard-copies of questionnaire and spread them to the random students of
English majors in Wuhan University of Technology in January, 2018. 78 hard-copies of questionnaire were collected after five days since they were sent out. 73 out of 78 hard-copies of questionnaire are valid. According to the 73 valid questionnaires, 21 students had used the Contemporary College English while 52 students had used A New English Course in their English-major course-English Intensive Reading.

\section{RESUlts}

\section{A. Results for Contemporary College English}

TABLE II RESUlTS OF QUESTIONS 5-14 FOR CONTEMPORARY COLLEGE ENGLISH

\begin{tabular}{|c|c|c|c|c|}
\hline Question No. & \multicolumn{4}{|c|}{ Number and percentage of the informants choosing the corresponding items } \\
\hline 5 & A. $21(100 \%)$ & B. 0 & C. 0 & \\
\hline 6 & A. $16(76.2 \%)$ & \multicolumn{2}{|l|}{ B. $5(23.8 \%)$} & C. 0 \\
\hline 7 & A. $21(100 \%)$ & B. 0 & C. 0 & D. 0 \\
\hline 8 & A. $1(4.8 \%)$ & B. $5(23.8 \%)$ & C. $1(4.8 \%)$ & D. $14(66.7 \%)$ \\
\hline 9 & A. $18(85.7 \%)$ & B. 0 & C. 0 & D. $3(14.3 \%)$ \\
\hline 10 & A. 0 & \multicolumn{3}{|l|}{ B. $21(100 \%)$} \\
\hline 11 & A. $3(14.3 \%)$ & B. $12(57.1 \%)$ & & $3.6 \%)$ \\
\hline 12 & A. $4(19 \%)$ & \multicolumn{3}{|l|}{ B. $17(81 \%)$} \\
\hline 13 & A. 0 & B. $21(100 \%)$ & C. 0 & D. 0 \\
\hline 14 & A. $12(57.1 \%)$ & \multicolumn{3}{|l|}{ B. $9(42.9 \%)$} \\
\hline
\end{tabular}

According to the results of the questionnaire (see Table 2.), in the Contemporary College English, mostly all of its passages come from renowned authors' great works. The passages in this textbook are difficult to understand. Take Question 11 for example. Only $14.3 \%$ students keep the confidence that they understand the whole passages. Half of the informants claim that they understand $70-90 \%$, while $28.6 \%$ state that they understand less than $70 \%$ of the passages. Therefore, the material that this textbook has chosen may not be easy for the senior students to understand. Some informants attribute the learning difficulty to the length of the passages in this textbook. Due to that there are more than 10 units, the students have no enough time to understand all the passages. From Question 6, we can find that $76.2 \%$ students give a high praise to this textbook, namely, it satisfies its intended audiences well. The Contemporary College English is successful in this aspect. From Question 7, this textbook has its own vocabulary list or index and receives positive comments from the informants.

The results for Question 8 reveal that most of the teachers focus on translation when they use this textbook, However, this textbook has no workbook, all the exercises are presented at the end of the units. More than half of the students complain about too much exercises, especially regarding the translation of sentences and paragraphs. In addition, the textbook has no enough space for writing. The results of Question 9 show that almost all the teachers use the textbook material through wordfor-word translation. From the response of the students, during the class, their teachers translated the passages word for word. During this process, the teacher explained the grammar and vocabulary. The process of translation took most of the time in one class. Then, the teacher requested the students to finish the tests and exercises, and later he or she would provide the correct answers. It is obvious that the teachers pay too much attention on the translation of the passages. The results of Question 10 indicate that the teachers prefer to use the same textbook with the students rather than the teacher's reference book in class. From Question 13, we can find that the textbook has its own radio and video materials, but all the teachers have never used them. According to Question 14, we can see that the difficulty level of the exercises is appropriate. 
The results for Questions 15-16 reveal that most of the students are not willing to conduct self-study with this textbook. However, the students are satisfied with the glossary. In general, the Contemporary College English is a successful textbook, and it meets most of the users' needs, although it remains several issues such as the length of the passages and the number of translation exercises.

\section{B. Results for A New English Course}

TABLE III REsults OF QUESTIONS 5-14 FOR A NEW ENGLISH COURSE

\begin{tabular}{|c|c|c|c|c|}
\hline Question No. & \multicolumn{4}{|c|}{ Number and percentage of the informants choosing the corresponding items } \\
\hline 5 & A. $10(19.2 \%)$ & \multicolumn{2}{|l|}{ B. $12(23.1 \%)$} & C. $30(57.7 \%)$ \\
\hline 6 & A. $38(73.1 \%)$ & \multicolumn{2}{|l|}{ B. $11(21.2 \%)$} & C. $3(5.8 \%)$ \\
\hline 7 & A. 0 & B. 0 & C. 0 & D. $52(100 \%)$ \\
\hline 8 & A. $11(21.2 \%)$ & B. $17(32.7 \%)$ & C. $8(15.4 \%)$ & D. $16(30.8 \%)$ \\
\hline 9 & A. $35(67.3 \%)$ & B. $2(3.8 \%)$ & C. 0 & D. $15(28.8 \%)$ \\
\hline 10 & A. $11(21.2 \%)$ & \multicolumn{2}{|c|}{ B. $41(78.8 \%)$} & \\
\hline 11 & A. $21(40.4 \%)$ & \multicolumn{2}{|l|}{ B. $31(59.6 \%)$} & C. 0 \\
\hline 12 & A. $12(23.1 \%)$ & \multicolumn{2}{|c|}{ B. $40(76.9 \%)$} & \\
\hline 13 & A. $3(5.8 \%)$ & B. $49(94.2 \%)$ & C. 0 & D. 0 \\
\hline 14 & A. $9(17.3 \%)$ & \multicolumn{2}{|c|}{ B. $43(82.7 \%)$} & \\
\hline
\end{tabular}

As shown in Table 3, A New English Course has more diversified types of passages (see the results of Question 5). The form of passages is similar to that of the questions in TEM-4 and TEM-8. According to the results for Question 6, more than half of the students give a high praise to this textbook. Generally speaking, this textbook satisfies its intended audience. From the results of Question 7, this textbook has no vocabulary list or index. This is considered as a weakness of $A$ New English Course. The results of Question 8 show that the textbook is highly balanced in all aspects of language skills including grammar, translation, and vocabulary.

From Question 9, we can find that almost all the teachers tend to use the same mode to analyze the passages. $67.3 \%$ students claim that their teachers translate the passages in this textbook word-by-word. It should be noted that this textbook has its own workbook, and some teachers use the workbook for teaching, almost accounting for $28.8 \%$. With respect to Question 10, most of the teachers do not like to use the teacher's book, and they prefer to use their own teaching notes. Regarding Question 11, the textbooks' materials are easy to understand, and all the students can understand more than $70 \%$ of the passages. For Question 12, although this textbook introduces a wide range of foreign culture, $76.9 \%$ students have no interests in taking the initiative to learn about the culture. In term of Question 13, the textbook has its own radio and video materials, but all the teachers have never used them.

According to the results of Question 15, regarding its choice of materials, this textbook is highly similar to the topics in TEM-4. For the students of English majors, it is beneficial that they can practice their reading skill of TEM-4 during the class. However, from the results of Questions 15-16, we can also find that the exercises are too easy for the students. This may not be helpful to enhancing the students' comprehensive use of English linguistic knowledge.
As shown above, the feedback from the informants regarding the questionnaire indicates that the Contemporary College English and A New English Course generally meet most of the learning demands of senior students from Englishmajors. The majority of the students provided positive or medium-level comments on the actual effects of the two textbooks. However, several issues remain in these two textbooks for further improvement. Most of the informants held the view that although the Contemporary College English contained a well-designed glossary, the passages were too difficult for the students to understand and it had too many translation exercises. On the contrary, the passages in $\mathrm{A} \mathrm{New}$ English Course were less difficult for the students to understand and the quantity of exercises was appropriate, but this textbook did not include a glossary.

Considering the heterogeneity of L2 classes, a successful ELT textbook needs to meet the demands of the students with different levels of L2 proficiency. This requires the provision of suitable passages, moderate exercises or practices, wellpresented structure and a variety of learning materials. The passages in the Contemporary College English appear to be fairly difficult to understand, and it has great number of translation exercises. It is really a good choice for those students who pursue to improve their literacy and translation skills. The passages and exercises in A New English Course are highly similar to the examination questions of TEM-4 and TEM-8. It is more suitable for students to cultivate their problem-solving skills. 


\section{CONCLUSION}

This study has carried out a retrospective evaluation to measure the actual effects of two ELT textbooks, Contemporary College English and A New English Course, which have been widely used for English-majors across Chinese universities. The current assessment may contribute to improving English teaching at a university level in China. We not only need to pay attention to the textbook selection, but also need to focus on the class interaction. Language teachers need to make a decision on the textbooks based on their teaching syllabi. The choice of textbooks should be also consistent with the users' needs. In addition, ELT textbooks need to provide more speaking exercises. During the interview of the informants, most of the students claimed that in the class of English Intensive Reading, they had no opportunity to exchange their ideas. Since there were too many passages in the textbooks, their teachers needed to skip the oral practices in order to catch up with the teaching progress. The students had to listen to their teacher all the time without interaction. This may not be beneficial to facilitating the students' English communication skills.

Some weaknesses associated with limitations beyond the control of the researcher within the restricted timeframe need to be identified. The questionnaire is limited in quantity and scope. More informants need to be investigated to extend the generalizability of the findings in this study. The descriptive nature of questions means that the textbook evaluation may be subjective both in its selection of criteria and in the judgements made by the reviewers. However, the questionnaire is easily understood and cost effective for the evaluators within the limited settings.

\section{REFERENCES}

[1] Ministry of Education. (2010). [Guidelines of the National Program for Medium- and Long-Term Educational Reform and Development (20102020)] (In Chinese). Retrieved from http://www.moe.gov.cn/srcsite/A01/s7048/201007/t20100729_171904.h tml

[2] Ministry of Education. (2012). [Some Opinions on Improving the Quality of Higher Education in All-Round Way] (In Chinese). Retrieved from

http://www.moe.gov.cn/srcsite/A08/s7056/201203/t20120316_146673.h tml

[3] Ministry of Education. (2017). [Guide to the College English Teaching] (In Chinese). Retrieved from https://wenku.baidu.com/view/69680453d1f34693dbef3e7a.html

[4] Harmer, J. (1991). The Practice of English Language Teaching. New York: Longman Publishing.

[5] McGrath, I. (2002). Materials evaluation and design for language teaching. Edinburgh: Edinburgh University Press.

[6] Garinger, D. (2002). Textbook Selection for the ESL Classroom. Retrieved from http://www.cal.org/resources/digest/0210garinger.html

[7] Harmer, J. (1996). The Practice of English Language Teaching. London: Longman.

[8] Mukundan, J., Hajimohammadi, R., \& Nimehchisalem, V. (2011). Developing an English Language Textbook Evaluation Checklist: A Focus Group Study. International Journal of Humanities and Social Science, 1(12), 100-106.

[9] Tang, X. (2017). Learnability and Pedagogical Implication: An Acquisition-Based Evaluation of English Textbooks in China. Canberra: Australian National University.

[10] McDonough, J., \& Shaw, C. (2003). Materials and methods in ELT: A teacher's guide. Oxford: Blackwell.

[11] Cunningsworth, A., \& Kusel, P. (1991). Evaluating teachers' guides. ELT Journal, 45(2), 128-139.

[12] Breen, M. P., \& Candlin, C. N. (1987). Which materials? A consumer's and designer's guide. In L. E. Sheldon (Ed.), ELT textbooks and materials: problems in evaluation and development. ELT Documents 126. London: Modern English Publications and the British Council.

[13] Ahmadi, A., \& Derakhshan, A. (2016). EFL teachers' perceptions towards textbook evaluation. Theory and Practice in Language Studies, $6(2), 12-25$.

[14] Asadi, M., Kiany, G. R., Akbari, R., \& Samar, R. G. (2016). Program evaluation of the new English textbook in the Iranian ministry of education. Theory and Practice in Language Studies, 6(2), 26-30.

[15] Rotich, D. C., Kogos, E. J., \& Geuza, Z. R. (2018). An Investigation of Textbook Vetting and Evaluation Process in Tanzania. Publishing Research Quarterly, 34(1), 96-109.

[16] Fraidan, A. A. (2012). Evaluation of Two ESP Textbooks. English Language Teaching, 5(6), 43.

[17] Shi, J., \& Ji, R. (2011). [The construction and application of evaluation system for English visual and verbal teaching materials] (In Chinese). Education Research Monthly, (05), 68-74.

[18] Yang, L. (2002). [The Contemporary College English] (In Chinese). Beijing: Foreign Language Teaching and Research Press.

[19] Gao, Y. (2009). [A New English Course] (In Chinese). Beijing: Beijing University Press. 